\title{
Результаты изучения различных форм виноградных кустов кордонного типа
}

\author{
Владимир Викторович Чулков, д-р с.-х. наук, профессор кафедры растениеводства и садоводства, dgau-web@mail.ru; \\ Вера Константиновна Мухортова, канд. с.-х. наук, старший преподаватель кафедры растениеводства и садоводства, \\ veramuhortova1987@yandex.ru \\ Башир Рамисович Мустафаев, аспирант очного обучения кафедры растениеводства и садоводства, \\ mustafaevbashir@mail.ru; \\ Федеральное государственное бюджетное образовательное учреждение высшего образования «Донской государственный аграрный \\ университет», Россия, 346493, Ростовская область, Октябрьский район, п. Персиановский, ул. Кривошлыкова, 24.
}

В статье приведены экспериментальные данные по изучению влияния различных форм виноградных кустов кордонного типа на рост, развитие и урожайность плодоносящих растений в орошаемых условиях Южного Дагестана. Анализ полученных экспериментальных данных показал, что форма виноградных кустов оказывала существенное влияние на степень роста однолетних побегов развивающихся на виноградных растениях в течение вегетационного периода. При этом кусты накапливали различный объем фитомассы однолетней лозы. Установлено, что в среднем за годы наблюдений объем фитомассы однолетних побегов у кустов сформированных по типу одностороннего горизонтального кордона находился на уровне $285,6 \mathrm{~cm}^{3}$, у кустов сформированных по типу двустороннего горизонтального кордона составил $415,7 \mathrm{~cm}^{3}$. В то же время у растений с формой двухъярусный горизонтальный кордон объем фитомассы однолетних побегов достигал $604,8 \mathrm{~cm}^{3}$. Следовательно, виноградные растения в 3 варианте опыта, в период проведения наблюдений, формировали более высокий биологический потенциал, который обеспечивал высокую продуктивность виноградных кустов. При анализе полученных экспериментальных данных установлено колебание плодоносных побегов на кусте в пределах от 20 до 33 шт. в зависимости от формы виноградного куста. При этом максимальное количество плодоносных побегов на уровне 29 - 33 шт. имели кусты винограда с формой двухъярусный горизонтальный кордон. В остальных вариантах опыта данный показатель был значительно ниже и находился на уровне 20 - 22 шт. на одном кусте в 1 варианте и 23 - 25 шт. во 2 варианте. В результате проведенных исследований установлено, что в среднем за период наблюдений более высокий урожай у технического сорта винограда Шардоне получен в 3 варианте опыта и составил 7,2 кг с 1 куста. Это на 25 - 37 \% выше, чем в остальных вариантах опыта.

Ключевые слова: виноград, штамб, горизонтальный кордон, побег, урожай, форма куста, сорт Шардоне.

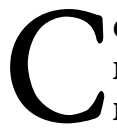
еверный Кавказ по совокупности прироАно-кииматических факторов явмяется оАним из наиболее перспективных районов Аля возделывания плодовых культур и винограда в Российской Федерации. В первую очередь это обусловлено благоприятными экологическими условиями Аанного района, позволяющими в максимацьной степени реализовать биомогиче-

\footnotetext{
Как цитировать эту статью:

Чулков В.В., Мухортова В.К., Мустафаев Б.Р. Результаты изучения различных форм виноградных кустов кордонного учения различных форм виноградных кустов кордонного типа// «Магарач». Виноградарство и ви
113-116. DOI 10.35547/IM.2019.21.2.007

How to cite this article:

Chulkov V.V., Mukhortova V.K., Mustafayev B.R. Study findings on different shapes of vines of the cordon type. Magarach Viticulture and Winemaking, 2019; 21(2); pp. 113-116. DOI 10.35547/IM.2019.21.2.007

удК 634.8:631.542.32
}

Поступила 11.02.2019

Принята к публикации 16.05.2019

(C) Авторы, 2019

\section{O R I G I N A L A R T I C L E \\ Study findings on different shapes of vines of the cordon type}

\author{
Vladimir Viktorovich Chulkov, Vera Konstantinovna \\ Mukhortova, Bachir Ramisovich Mustafayev \\ Federal State Budget Educational Institution of Higher Education Don \\ State Agrarian University, Str. Krivoshlykova, 24, Persianovskiy village, \\ Oktyabrsky Region, Rostov Oblast, Russia, 346493.
}

The article presents experimental data on the study of the effect of different shapes of cordon-type vine bushes on the growth, development and yield of fruit-bearing plants in irrigated conditions of southern Dagestan. Experimental data analysis revealed that the vine bush shape had a significant impact on the growth rate of annual shoots developing on vine plants during vegetation period. Furthermore, the bushes accumulated different volume of one year old shoot phytomass. It was found that, on average, over the years of observations, the phytomass volume of one-year shoots on bushes trained as unilateral horizontal cordon was at the level of $285.6 \mathrm{~cm}^{3}$, on the bushes trained as bilateral horizontal cordon it reached $415.7 \mathrm{~cm}^{3}$. At the same time, the plants trained as two-tiered horizontal cordon developed the phytomass volume of one-year shoots of $604.8 \mathrm{~cm}^{3}$. Therefore, over the observation period, the vine plants in the third trial variant developed a higher biological potential that ensured high productivity of the vine bushes. Experimental data analysis determined fluctuation of the fruit-bearing shoots on a bush within the range of 20 to 33 pcs. depending on the vine shape training. Whereby, vine bushes trained as two tier horizontal cordon had the maximum number of fertile shoots, specifically $29-33$ pcs. In other variants of the experiment, this indicator was much lower and constituted 20-22 pcs. per one bush in the 1st variant and 23-25 pcs. in the 2 nd variant. Thus, the study established that, on average, over the observation period, wine cultivar 'Chardonnay' produced a higher yield in the $3 \mathrm{~d}$ variant of the experiment, specifically $7.2 \mathrm{~kg}$ per $1 \mathrm{bush}$. This is by $25-37 \%$ higher as compared to the other trial versions.

Keywords: vine, vine, trunk, horizontal cordon, shoot, harvest, vine shape, 'Chardonnay' cultivar..

ский потенциал виноградных растений.

По Аанным многих ученых [1-6], занимавшихся изучением культуры винограда в Северо-Кавказском регионе, установлено, что Аля промышкенных насажАений наибомее перспективными явмяются высокоштамбовые формы виноградных кустов. Применение этих форм кустов на промышкенных виноградниках обеспечивает мучшее использование растениями факторов окружающей среды, эффективное перераспределение питательных веществ в пользу хозяйственно ценных органов, снижение затрат ручного труда по уходу за виноградными кустами, а также позволяет широко применять средства механизации на основных производственных процессах.

В связи с этим разработка более продуктивных форм виноградных кустов при выращивании технического сорта Шардоне на виноградниках Южного Аагестана обеспечит более высокую урожайность промышленных насаждений и будет способствовать эффективному развитию отрасли. 
Study findings on different shapes of vines of the cordon type.

Целью исследований являлось определение эффективной формы виноградных кустов корАонного типа ААя технического сорта ШарАоне на виноградниках Южного Аагестана.

Исследования проводили в 2016-2018 гг. на виноградниках 2012 года посадки в ООО АЗИВ-2, находящемся в Аербентском районе Республики Аагестан. Схема посадки кустов $3 \times 1,5$, виноградные кусты привиты на подвое Кобер 5 ББ. Участок орошаемый. Исследования проводили на техническом сорте винограда Шардоне.

В процессе изучения испытывали следующие формы виноградных кустов: 1 вариант - оАносторонний Горизонтальный корАон с высотой штамба 120 см; 2 вариант - Авусторонний горизонтальный корАон с высотой штамба 120 см; 3 вариант -Авухъярусный горизонтальный кордон с высотой штамбов 120 и $160 \mathrm{~cm}$.

Все учеты и наблюдения проводили согласно принятым в виноградарстве методикам [7].

Как показывает многолетний опыт выращивания винограда, среди агротехнических приемов, применяемых в промышленных насаждениях, важная роль отводится формированию виноградных кустов. Это обусловлено тем, что форма виноградного куста во многом влияет на условия роста и развития растений, в значительной степени определяет характер размещения основных структурных экементов кустов на шпалере.

Рационацьным формированием, обрезкой и размещением $\Lambda 03$, отвечающим экологическим условиям и биологическим особенностям сортов, можно создавать и поААерживать наиболее благоприятные условия Аля роста и плодоношения винограда.

При проведении исследований по определению наиболее эффективного способа формирования винограАных кустов ААя технического сорта Шардоне мы исходили из того, что пАОАОНОшение и продуктивность насаждений в первую очередь зависят от величины биологического потенциала растений.

Поскольку биологический потенциал

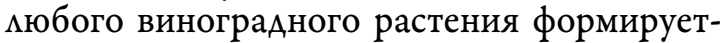
ся с момента посадки на постоянное место Ао его вступцения в полное плодоношение, бымо проведено определение данного показателя у растений во всех вариантах опыта. При этом мы исходили из того, что этот важный биологический показатель наиболее полно отражает величина объема фитомассы однолетнего прироста, ежегодно формирующегося на кусте в течение вегетационного периода. В первую очередь это обусмовлено тем, что в процессе роста и развития вино-
Chulkov V.V., Mukhortova V.K.

Mustafayev B.R

VITICULTURE

Таблица 1. Степень развития однолетнего прироста при различных типах форм виноградных кустов сорта Шардоне.

Table 1 . The degree of one-year increment development under various types of vine bush training in the case of 'Chardonnay' cultivar.

\begin{tabular}{|c|c|c|c|c|c|c|c|c|}
\hline 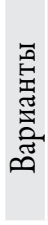 & Форма куста & $\begin{array}{l}\text { Коми- } \\
\text { чество } \\
\text { штам- } \\
\text { бов, } \\
\text { шт. }\end{array}$ & $\begin{array}{l}\text { Годна- } \\
\text { бцюАе- } \\
\text { ний }\end{array}$ & $\begin{array}{l}\text { СреА- } \\
\text { няя } \\
\text { А ина } \\
\text { побе- } \\
\text { га, см }\end{array}$ & $\begin{array}{l}\text { СреА- } \\
\text { ний } \\
\text { Аиа- } \\
\text { метр } \\
\text { побега, } \\
\text { мм }\end{array}$ & $\begin{array}{l}\text { Коми- } \\
\text { чество } \\
\text { побе- } \\
\text { гов на } \\
\text { кусте, } \\
\text { шт. }\end{array}$ & $\begin{array}{l}\text { Сте- } \\
\text { пень } \\
\text { вызре- } \\
\text { вания } \\
\text { побега, } \\
\%\end{array}$ & $\begin{array}{l}\text { Объем } \\
\text { по- } \\
\text { бегов } \\
\text { куста, } \\
\text { см }^{3}\end{array}$ \\
\hline \multirow{4}{*}{1} & \multirow{4}{*}{$\begin{array}{l}\text { ОАносторонний } \\
\text { горизонтацьный } \\
\text { корАон }\end{array}$} & \multirow{4}{*}{1} & 2016 & 130 & 5,7 & 32 & 76 & 249,6 \\
\hline & & & 2017 & 143 & 6,1 & 28 & 81 & 360,4 \\
\hline & & & 2018 & 135 & 5,8 & 30 & 77 & 324,0 \\
\hline & & & среднее & 136 & 5,9 & 30 & 78 & 285,6 \\
\hline & \multirow{4}{*}{$\begin{array}{l}\text { Авусторонний } \\
\text { горизонта цьный } \\
\text { кордон }\end{array}$} & \multirow{4}{*}{1} & 2016 & 147 & 6,0 & 30 & 80 & 396,9 \\
\hline & & & 2017 & 152 & 6,2 & 29 & 85 & 396,9 \\
\hline & & & 2018 & 148 & 6,1 & 33 & 81 & 439,6 \\
\hline & & & среднее & 149 & 6,1 & 31 & 82 & 415,7 \\
\hline & \multirow{4}{*}{$\begin{array}{l}\text { Авухъярусный } \\
\text { горизонта ььный } \\
\text { кордон }\end{array}$} & \multirow{4}{*}{2} & 2016 & 136 & 5,9 & 44 & 77 & 478,7 \\
\hline & & & 2017 & 145 & 6,1 & 48 & 83 & 626,4 \\
\hline & & & 2018 & 139 & 6,0 & 52 & 80 & 650,5 \\
\hline & & & среднее & 140 & 6,0 & 48 & 80 & 604,8 \\
\hline
\end{tabular}

градного растения идет формирование его вегетативных органов и, следовательно, их величина свидетельствует о способности куста накапливать определенный объем фитомассы, необходимой ААя ПоААерЖания в активном состоянии всех физиомогических функций винограАного растения.

Результаты проведенных наблюдений, представленные в табл. 1, свидетельствуют о значительном влиянии формы кустов на степень развития однолетнего прироста.

Учеты степени развития однолетних побегов на плодоносящих кустах винограда сорта Шардоне проводили одновременно во всех вариантах опыта в конце периода вегетации, после полного прекращения роста однолетней мозы. При этом опреАелями общее число побегов на кусте, Алину и толщину побегов, а также степень их вызревания.

Как показали наблюАения, количество побегов на кустах винограда в годы проведения исследований в среАнем колебамось в пределах от 30 Ао 48 шт. При этом максимальное количество побегов несли кусты винограда с формой «двухъярусный горизонтальный корАОн》, что было связано с большей общей Алиной горизонтальных рукавов, поскольку они размещались в Авух ярусах. В остальных вариантах опыта горизонтальные рукава размещались на одном ярусе шпалерной проволоки и их Алина быма меньше. В результате этого, как односторонний, так и Авусторонний горизонтальные кордоны формировали меньше оАнолетних побегов.

Экспериментальные Аанные, характеризующие степень развития однолетних побегов у разАичных форм виноградных кустов, свидетельствуют о более активном росте однолетней мозы у кустов, сформированных по типу двухстороннего горизонтального корАона. В этом варианте опыта среАняя Алина по- 
бега за годы набцюдений в среАнем составима 149 см при Аиаметре 6,1 мм.

В то же время в остацьных вариантах опыта виноградные растения уступали по Алине и толщине оАнолетних побегов. Так, если в 1 варианте опыта при форме кустов оАносторонний горизонтацьный корАон Алина побега в среднем за годы наблюдений составима 136 см, при среднем диаметре козы 5,9 мм, то в 3 варианте при форме виноградных кустов Авухъярусный горизонтацьный корАон среАняя Алина побега находимась на уровне $140 \mathrm{~cm}$, а среАний Аиаметр побега составця 6,0 мм. Сокращение Алины и Аиаметра однолетних побегов у кустов в 3 варианте опыта происходимо из-за значительного увемичения нагрузки кустов побегами. Приведенные в табл. 1 экспериментацьные данные свидетельствуют о том, что число побегов на кустах в 3 варианте опыта на 35-37\% превышала их количество в 1 и 2 варианте.

Поскольку Аиина и толщина побегов, развившихся на виноградных кустах, не позвоцяют в полной мере суАить о потенциале растения, мы провели определение объема фитомассы однолетнего прироста развивающегося на опытных растениях. Полученные результаты свидетельствуют о более мощном развитии виноградных растений, сформированных по типу Авухъярусного горизонтацьного кордона. В этом варианте опыта объем фитомассы однометнего прироста в среднем за годы наблюдения составиц $604,8 \mathrm{~cm}^{3}$, что на $31-53 \%$ больше, чем у растений в остацьных вариантах опыта.

Ввиду того, что форма виноградного куста способна оказывать опредеменное вцияние на основные процессы жизнедеятемьности растений, бымо проведено изучение особенностей формирования плодоносных органов, урожая и качества ягод у опытных растений.

При анацизе полученных экспериментацьных Аанных установцено комебание плодоносных побегов на кусте в пределах от 20 Ао 33 шт. в зависимости от формы виноградного куста (табц. 2).

При этом максимацьное комичество плодоносных побегов на уровне 29-33 шт. имели кусты винограда с формой Авухъярусный горизонтацьный корАон. В остацьных вариантах опыта Аанный показатемь был значительно ниже и находился на уровне 20-22 шт. на одном кусте в 1 варианте и 23-25 шт. во 2 варианте.

Аля опредемения эффективности той ими иной формы винограАного куста принято учитывать урожай гроздей. Учет вемичины урожая по вариантам опыта проводи$\Lambda$ и в период уборки урожая.
Таблица 2. Влияние формы виноградных кустов на урожай и качество гроздей сорта Шардоне.

Table 2. The impact of the vine bush training on the yield and quality of bunches of 'Chardonnay' cultivar.

\begin{tabular}{|c|c|c|c|c|c|c|c|c|}
\hline \multirow{2}{*}{ 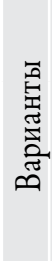 } & \multirow{2}{*}{ Форма куста } & \multirow{2}{*}{$\begin{array}{l}\text { Коми- } \\
\text { чество } \\
\text { штам- } \\
\text { бов, } \\
\text { шт. }\end{array}$} & \multirow[b]{2}{*}{$\begin{array}{l}\text { ГоА } \\
\text { набцю- } \\
\text { Аений }\end{array}$} & \multirow{2}{*}{$\begin{array}{l}\text { Коми- } \\
\text { чество } \\
\text { побегов } \\
\text { на ку- } \\
\text { сте, шт. }\end{array}$} & \multirow{2}{*}{$\begin{array}{l}\text { Коми- } \\
\text { чество } \\
\text { пцодо- } \\
\text { носных- } \\
\text { побегов } \\
\text { на кусте, } \\
\text { шт. }\end{array}$} & \multirow{2}{*}{$\begin{array}{l}\text { Уро- } \\
\text { жай } \\
\text { с } 1 \\
\text { куста, } \\
\text { кг }\end{array}$} & \multicolumn{2}{|c|}{$\begin{array}{l}\text { Массовая кон- } \\
\text { центрация }\end{array}$} \\
\hline & & & & & & & $\begin{array}{l}\text { сахаров, } \\
\Gamma / 100 \mathrm{~cm}^{3}\end{array}$ & $\begin{array}{l}\text { кис- } \\
\Lambda о т, ~ \\
\text { г/Ам }\end{array}$ \\
\hline \multirow{4}{*}{1} & \multirow{4}{*}{\multicolumn{2}{|c|}{$\begin{array}{l}\text { ОАносторонний } \\
\text { горизонтацьный } 1 \\
\text { кордон }\end{array}$}} & 2016 & 32 & 21 & 4,5 & 20,1 & 7,4 \\
\hline & & & 2017 & 28 & 20 & 4,3 & 20,4 & 7,3 \\
\hline & & & 2018 & 30 & 22 & 4,7 & 21,1 & 7,2 \\
\hline & & & среднее & 30 & 21 & 4,5 & 20,5 & 7,3 \\
\hline \multirow{4}{*}{2} & \multirow{4}{*}{\multicolumn{2}{|c|}{$\begin{array}{l}\text { Авусторонний } \\
\text { горизонтацьный } 1 \\
\text { кордон }\end{array}$}} & 2016 & 30 & 24 & 5,1 & 22,0 & 6,8 \\
\hline & & & 2017 & 29 & 23 & 5,3 & 21,9 & 7,0 \\
\hline & & & 2018 & 33 & 25 & 5,6 & 22,4 & 7,0 \\
\hline & & & среАнее & 31 & 24 & 5,4 & 22,1 & 6,9 \\
\hline \multirow{4}{*}{3} & \multirow{4}{*}{\multicolumn{2}{|c|}{$\begin{array}{l}\text { Авухъярусный } \\
\text { горизонта ььный } 2 \\
\text { кордон }\end{array}$}} & 2016 & 44 & 29 & 6,8 & 20,8 & 6,7 \\
\hline & & & 2017 & 48 & 33 & 7,5 & 21,3 & 6,9 \\
\hline & & & 2018 & 52 & 32 & 7,4 & 21,5 & 7,0 \\
\hline & & & среАнее & 48 & 31 & 7,2 & 21,2 & 6,9 \\
\hline \multicolumn{3}{|c|}{$\mathrm{HCP}_{05}$} & & & 1,6 & 0,7 & 1,1 & 0,8 \\
\hline
\end{tabular}

В результате анациза полученных экспериментальных Аанных более высокий урожай с 1 куста в годы исследований получен у виноградных растений, сформированных по типу Авухъярусного горизонтацьного кордона, и составим в среАнем 7,2 кг. В то же время у кустов винограАа, сформированных по типу одностороннего горизонтацьного кордона, вецичина урожая находи$\Lambda$ ась на уровне 4,5 кг, а у кустов с формой Авусторонний горизонтальный кордон - на уровне 5,4 кг.

Наряду с величиной урожая важным показателем, характеризующим эффективность формы виноградного куста при возАелывании технических сортов винограда, явцяется качество винограда, так как от этого в конечном итоге зависят органолептические и физико-химические показатели продуктов его переработки.

Как показаци исследования, содержание сахаров в соке ягод по вариантам опыта в среднем за период наблюдений находимось в преАелах от 20,5 Ао 22,1 г/100 см³, при содержании органических кислот на уровне 6,9-7,3 г/ $\mathrm{AM}^{3}$.

Таким образом, проведенными исследованиями установмено, что в орошаемых условиях Южного Аагестана наиболее эффективной формой винограАных кустов ААя технического сорта ШарАоне является Авухъярусный горизонтацьный кордон. Кусты Аанного типа позвомяют растениям в течение вегетации накапливать бомьший объем фитомассы однолетнего прироста, повышают закладку плодоносных органов и обеспечивают получение высокого урожая гроздей хорошего качества.

\section{Источник финансирования}

Не указан. 
Financing source Not specified.

Конфликт интересов Не заявлен.

\section{Conflict of interests} Not declared.

\section{Список литературы / References}

1. Жуков, А.И. Перспективные формировки винограда / А.И. Жуков // Инновационные технологии и тенденции в развитии и формировании современного виноградарства и виноделия. - Анапа, 2013. № 4. - C. 72-76.

ZHukov A. I. Perspektivniye formirovki vinograda Sb. Innovacionnye tekbnologii i tendencii v razvitii i formirovanii sovremennogo vinogradarstua $i$ vinodeliya [Sb. Innovative technologies and trends in development and formation of modern wine growing and winemaking]. -Anapa, 2013. No. 4. pp. 72-76. (in Russian)

2. Матузок, Н. В. Инновационная технология возделывания винограда в неукрывной зоне/ Н. В. Матузок, Л. М. Малтабар // Виноделие и виноградарство. - 2010. № 1. - С. 48.

Matuzok N.V., Maltabar L.M. Innovacionnaya tekhnologiya vozdelyvaniya vinograda $v$ neukryunoj zone. Vinodelie $i$ vinogradarstvo [Winemaking and wine growing]. - 2010. No. 1. P. 48. (in Russian)

3. Матузок, Н. В. Новационные формы кустов КубГАУ в виноградарстве / Н. В. Матузок, Л. П. Трошин // Современные системы земледелия в садоводстве и виноградарстве: Сб. науч.трудов ГНУ СКЗНИИСиВ. - Краснодар: ГНУ СКЗНИИСиВ, 2014. - Т.6. - С. 171-176.

Matuzok N.V., L.P. Troshin Novacionnye formy kustov KubGAU v vinogradarstve. Nauchnye trudy GNU SKZNIISiV. Sovremennye sistemy zemledeliya $v$ sadovodstve $i$ vinogradarstve [The modern systems of agriculture in gardening and wine growing // Scientific works of GNU SKZNIISiV]. - Krasnodar: GNU SKZNIISiV, 2014. V.6. - pp.171-176. (in Russian)

4. Мухортова, В.К. Сравнительная оценка способов обрезки неукрывных виноградников в Ростовской области / В. К. Мухортова, В. В. Чулков // Плодоводство и ягодоводство России: Сб. научных работ. - М., 2015. - Т. XXXXIII. - C. 321-323.
Mubortova V.K., CHulkov V.V. Sravnitel'naya ocenka sposobov obrezki neukryunyh vinogradnikov v Rostovskoj oblasti. Plodovodstvo i yagodovodstvo Rossii: sbornik nauchnyb rabot. - Moscow, 2015. T. XXXXIII. - P. 321-323. (in Russian)

5. Петров, В. С. Эффективные способы ведения кустов винограда в современных системах земледелия / В. С. Петров, Т. В. Павлюкова // Современные системы земледелия в садоводстве и виноградарстве: Сб. науч.трудов ГНУ СКЗНИИСиВ. - Краснодар: ГНУ СКЗНИИСиВ, 2014. - Т. 6. - С. 148-155.

Petrov V.S., Pavlyukova T.V. Effektivnye sposoby vedeniya kustov vinograda $v$ souremennyb sistemab zemledeliva. Nauchnye trudy GNU SKZNIISiV. Souremennye sistemy zemledeliva $v$ sadovodstve $i$ vinogradarstve // Scientific works of GNU SKZNIISiV]. - Krasnodar: GNU SKZNIISiV, 2014. V. 6. pp. 148-155. (in Russian)

6. Чулков, В. В. Исследование различных вариантов контурной обрезки штамбовых виноградников в условиях Нижнего Дона / В. В. Чулков, В. К. Мухортова // Инновационные технологии в плодоводстве, овощеводстве и декоративном садоводстве: Междунар. науч.-практич.конф., ФГБОУ ВО Воронежский ГАУ. - Воронеж, 2015. - C. 102-107.

Chulkov V.V., Muhortova V.K. Issledovanie razlichnyb variantov konturnoj obrezki shtambovyh vinogradnikov v usloviyab Nizhnego Dona. Mezbdunarodnaya nauchno-prakticheskaya konferenciya: "Innovacionnye tekhnologii v plodovodstve, ovoshchevodstve $i$ dekorationom sadovodstve", FGBOU VO Voronezhskij GAU [The International scientific and practical conference: "Innovative technologies in fruit growing, vegetable growing and decorative gardening"FGBOOU WAUGH Voronezh GAU]. Voronezh, 2015. - pp. 102-107. (in Russian)

7. Моисейченко, В. Ф. Основы научных исследований в плодоводстве, овощеводстве и виноградарстве / В. Ф. Моисейченко, А. Х. Завирюха, М. Ф. Трифонова. - М.: Колос, 1994. - 383

Moisejchenko V.F., Zaviryuba A.H., Trifonova M.F. Osnovy nauchnyb issledovanij v plodovodstve, ovoshchevodstve i vinogradarstve. Moscow: Kolos, 1994. 383 p. (in Russian) 